\title{
Polycystic ovary syndrome (PCOS) and the risk of coronary heart disease (CHD): a meta-analysis
}

\author{
Luqian Zhao', Zhigang Zhu ${ }^{1}$, Huiling Lou ${ }^{1}$, Guodong Zhu ${ }^{1}$, Weimin Huang ${ }^{1}$, \\ Shaogang Zhang ${ }^{1}$ and Feng Liu ${ }^{1}$ \\ ${ }^{1}$ Department of Geriatrics, Guangzhou First People's Hospital, Guangzhou Medical University, Guangzhou, Guangdong, China \\ Correspondence to: Feng Liv, email: gzsylnklf123@tom.com \\ Keywords: PCOS; cardiovascular disease; association; meta-analysis; Pathology Section \\ Received: April 03, $2016 \quad$ Accepted: May 13, $2016 \quad$ Published: May 22, 2016
}

\section{ABSTRACT}

Some studies reported a significant association between polycystic ovary syndrome (PCOS) and risk of cardiovascular disease (CVD). However, the results are controversial. A systematic search was conducted in the PubMed, Science Direct, EMBASE, and Cochrane Library databases. Five case-control studies and 5 cohort studies were selected, involving a total of 104392 subjects in this meta-analysis. PCOS was significantly associated with the increased risk of CVD (OR $=1.30 ; 95 \%$ CI $1.09-1.56 ; P=0.004)$. In the subgroup analysis of study design, both casecontrol studies and prospective cohort studies showed significant results $(O R=1.79$; 95\% CI 1.16 - 2.77; $P=0.009 ;$ OR = 1.20; 95\% CI $1.06-1.37 ; P=0.005$ ), while retrospective cohort studies did not show positive result (OR $=0.91 ; 95 \% \mathrm{CI} 0.60-$ 1.40; $P=0.68$ ). In a further stratified analysis by type of CVD, a significant association was found between PCOS and coronary heart disease (CHD) (OR $=1.44 ; 95 \% \mathrm{CI}$ $1.13-1.84 ; P=0.004)$. However, no significant association was observed between PCOS and myocardial infarction (MI) (OR = 1.01; 95\% CI $0.68-1.51 ; P=0.95)$. In conclusion, this meta-analysis suggested that PCOS is significantly associated with increased CHD risk.

\section{INTRODUCTION}

Polycystic ovary syndrome (PCOS) is one of the most common cause of infertility in women population [1]. Around $4 \%$ of unselected population of reproductive age and $7 \%$ of the caucasian population is believed to have this syndrome [2]. It is reported that PCOS patients had increased risk of many diseases, such as diabetes and infertility [3].

Cardiovascular disease (CVD) is one of the most common cause of mortality worldwide. Previous studies suggested that there will be more than 23 million CVD patients by 2030 [4-6]. The association between PCOS and risk of CVD has been reported by some studies. However, the results are controversial [7-16]. We thus did a metaanalysis and summarized the evidence on the incidence of CVD that has been studied in its association with PCOS.

\section{RESULTS}

Characteristics of eligible studies

A total of 121 potential studies were found by searching online databases, such as PubMed, Web of Science, Science Direct, EMBASE, and Cochrane Library. Five case-control studies and five cohort studies were selected in this study. A total of 104392 subjects were included in this meta-analysis. The detailed literature search strategy was showed in Figure 1. The baseline characteristics, such as author name, publication year, ethnicity, design, age, outcomes, sample size, and covariants were depicted in Table 1. The quality of the studies was acceptable. 
Table 1: Characteristics of the included studies

\begin{tabular}{|c|c|c|c|c|c|c|c|c|c|}
\hline & & Study & & & $\begin{array}{l}\text { Follow- } \\
\text { up }\end{array}$ & Sample & & & $\begin{array}{l}\text { Newcastle- } \\
\text { Ottawa }\end{array}$ \\
\hline $\begin{array}{l}\text { First } \\
\text { author }\end{array}$ & Year & design & Race & Age & years & size & Outcomes & Covariants & Scale \\
\hline $\begin{array}{l}\text { Birdsall } \\
{[7]}\end{array}$ & 1997 & $\mathrm{CC}$ & Caucasian & 52.3 & NA & 142 & MI & NA & 7 \\
\hline Cibula [8] & 2000 & $\mathrm{CC}$ & Caucasian & 52 & NA & 780 & CHD & $\mathrm{NA}$ & 5 \\
\hline Wild [9] & 2000 & $\mathrm{CC}$ & Caucasian & 56.7 & NA & 1379 & CHD & BMI & 4 \\
\hline $\begin{array}{l}\text { Solomon } \\
{[10]}\end{array}$ & 2002 & $\mathrm{PC}$ & Caucasian & $20-35$ & 14 & 82439 & CHD & $\begin{array}{l}\text { Age, BMI, cigarette } \\
\text { smoking, menopausal status/ } \\
\text { postmenopausal hormone } \\
\text { use, parential history of MI } \\
\text { before age } 60 \text { yr, parity, } \\
\text { alcohol intake, aspirin use, } \\
\text { multivitamin use, vitamin } \\
\text { E supplement use, physical } \\
\text { activity level, and history of } \\
\text { oral contraceptive use }\end{array}$ & 6 \\
\hline $\begin{array}{l}\text { Krentz } \\
{[11]}\end{array}$ & 2007 & $\mathrm{CC}$ & Caucasian & 73.8 & NA & 713 & $\begin{array}{l}\text { CVD, } \\
\text { CHD }\end{array}$ & NA & 7 \\
\hline $\begin{array}{l}\text { Lunde } \\
{[12]}\end{array}$ & 2007 & $\mathrm{CC}$ & Caucasian & 49.8 & NA & 854 & MI & NA & 4 \\
\hline $\begin{array}{l}\text { Schmidt } \\
\text { [13] }\end{array}$ & 2011 & $\mathrm{PC}$ & Caucasian & 70.4 & 21 & 127 & CVD, MI & NA & 7 \\
\hline $\begin{array}{l}\text { Wang } \\
{[14]}\end{array}$ & 2011 & $\mathrm{PC}$ & Mixed & 26 & 40 & 15005 & $\begin{array}{l}\text { CVD, } \\
\text { CHD }\end{array}$ & $\begin{array}{l}\text { Age, race, BMI, parity, } \\
\text { current tobacco use, and oral } \\
\text { contraceptive use }\end{array}$ & 8 \\
\hline $\begin{array}{l}\text { Iftikhar } \\
{[15]}\end{array}$ & 2012 & $\mathrm{RC}$ & Caucasian & 46.7 & 21 & 652 & CVD, MI & $\begin{array}{l}\text { Age at last follow-up, } \\
\text { BMI, infertility treatment, } \\
\text { postmenopausal hormone } \\
\text { therapy, and family history of } \\
\text { hypertension }\end{array}$ & 7 \\
\hline Mani [16] & 2013 & $\mathrm{RC}$ & Caucasian & 36 & 7 & 2301 & MI & $\begin{array}{l}\text { Age, BMI, Index of } \\
\text { Multiple Deprivation as a } \\
\text { marker of socio-economic } \\
\text { status, hyperandrogenism, } \\
\text { anovulation, ethnicity, smoking } \\
\text { and history of hypertension }\end{array}$ & 7 \\
\hline
\end{tabular}

CC, case-control study; PC, prospective cohort study; RC, retrospective cohort study; CVD, cardiovascular disease; CHD, coronary heart disease; MI, myocardial infarction; BMI, body mass index; NA, not available.

\section{Association of PCOS and risk of CVD}

As shown in Figure 2, PCOS patients had significantly increased risk of CVD $(\mathrm{OR}=1.30 ; 95 \% \mathrm{CI}$ $1.09-1.56 ; P=0.004)$. In the subgroup analysis of study design, both case-control studies and prospective cohort studies showed significant results $(\mathrm{OR}=1.79 ; 95 \% \mathrm{CI}$ 1.16 - 2.77; $P=0.009 ;$ OR $=1.20 ; 95 \%$ CI $1.06-1.37$; $P=0.005)$, while retrospective cohort studies did not show positive result $(\mathrm{OR}=0.91 ; 95 \%$ CI $0.60-1.40 ; P=$ $0.68)$. In a further subgroup analysis by the type of CVD, PCOS patients had significantly increased risk of coronary heart disease (CHD) $(\mathrm{OR}=1.44 ; 95 \%$ CI $1.13-1.84 ; P=$ $0.004)$. However, PCOS patients did not have significantly increased risk of myocardial infarction $(\mathrm{MI})(\mathrm{OR}=1.01$; $95 \%$ CI $0.68-1.51 ; P=0.95)$. In addition, both large sample size studies and small sample size studies showed significant results $(\mathrm{OR}=1.18 ; 95 \%$ CI $1.04-1.34 ; P$ $=0.01 ; \mathrm{OR}=1.64 ; 95 \% \mathrm{CI} 1.12-2.41 ; P=0.01)$. The results were showed in Table 2.

Sensitivity analysis suggested that the results of this study were statistically reliable (Figure 3 ). As shown in Figure 4, one study was the outlier [8]. After excluding this study, no heterogeneity was found $\left(\mathrm{I}^{2}=0 \%, P=\right.$ 0.74). Furthermore, the result was not influenced (OR $=1.22,95 \%$ CI $1.10-1.36, P=0.0003)$. In addition, Begg's funnel plot (Figure 5) and Egger's test indicated no significant publication bias $(P=0.261)$.

\section{DISCUSSION}

This is a meta-analysis which aimed to clarify the 


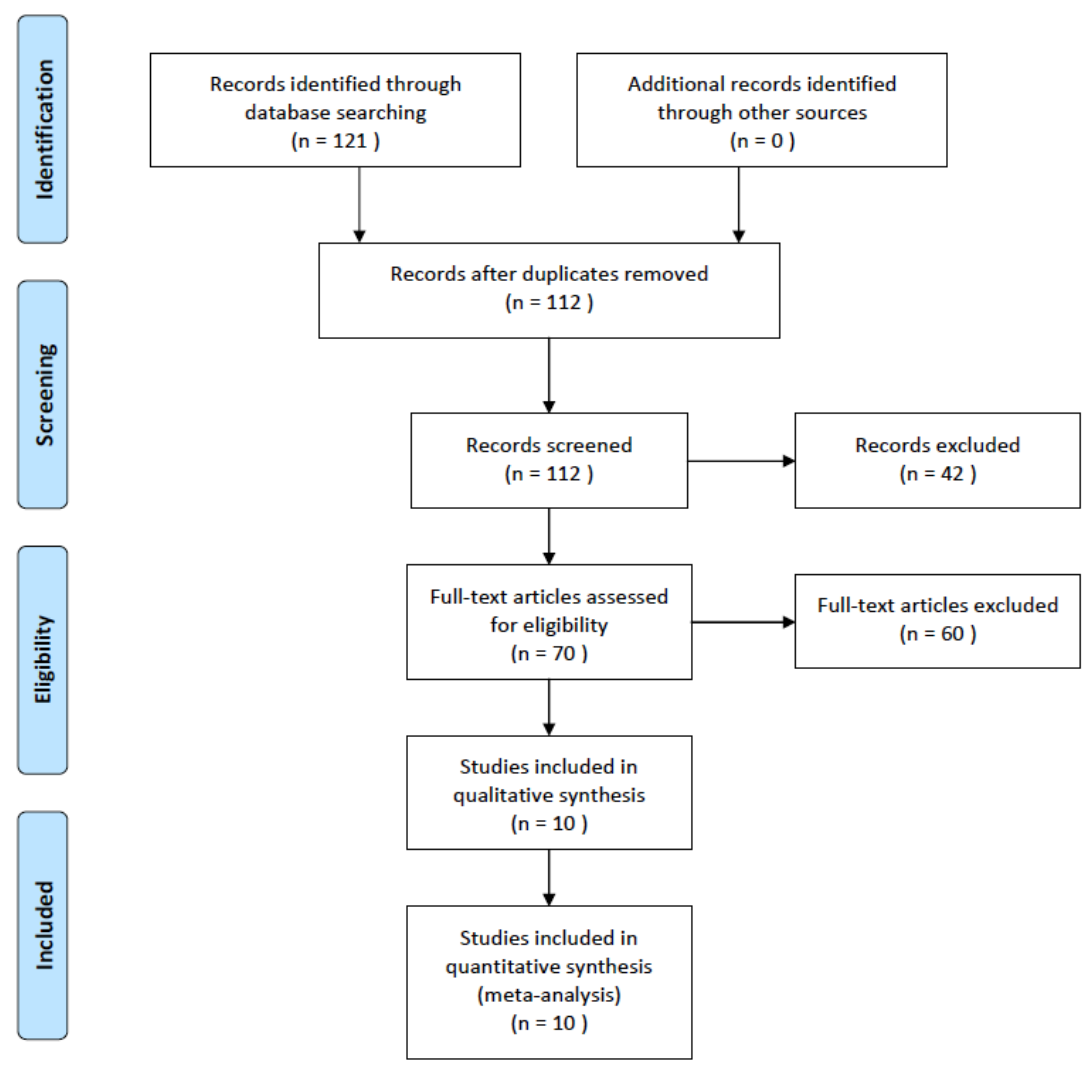

Figure 1: The selection of included studies.

\begin{tabular}{|c|c|c|}
\hline Study & & $\%$ \\
\hline ID & $\mathrm{OR}(95 \% \mathrm{Cl})$ & Weight \\
\hline Birdsall 1997 & $1.58(0.77,3.23)$ & 5.30 \\
\hline Cibula 2000 & $4.24(1.96,9.17)$ & 4.68 \\
\hline Wild 2000 & $1.50(0.70,3.21)$ & 4.78 \\
\hline Solomon 2002 & $1.22(1.04,1.43)$ & 26.17 \\
\hline Krentz 2007 & $1.36(1.05,1.76)$ & 19.62 \\
\hline Lunde 2007 & $2.80(0.10,78.39)$ & 0.29 \\
\hline Wang 2011 & $1.14(0.91,1.43)$ & 21.74 \\
\hline Schmidt 2011 & $1.93(0.76,4.94)$ & 3.31 \\
\hline Iftikhar 2012 & $1.03(0.59,1.80)$ & 7.94 \\
\hline Mani 2013 & $0.77(0.40,1.48)$ & 6.16 \\
\hline Overall (I-squared $=40.0 \%, p=0.091$ ) & $1.30(1.09,1.56)$ & 100.00 \\
\hline NOTE: Weights are from random effects analysis & & \\
\hline $\begin{array}{c} \\
.0128\end{array}$ & $\begin{array}{l}7 \\
8.4\end{array}$ & \\
\hline
\end{tabular}

Figure 2: Meta-analysis of the association between PCOS and CVD. 
Table 2: Results of this meta-analysis.

\begin{tabular}{|l|l|l|l|l|l|}
\hline & No. of study & OR $(\mathbf{9 5} \%$ CI $)$ & $\boldsymbol{P}$ Value & $\boldsymbol{I}^{\mathbf{2}}(\mathbf{\%})$ & $\boldsymbol{P}$ Value \\
\hline CVD & 10 & $1.30(1.09-1.56)$ & 0.004 & 40 & 0.09 \\
\hline Study design & & & & & \\
\hline CC & 5 & $1.79(1.16-2.77)$ & 0.009 & 48 & 0.11 \\
\hline PC & 3 & $1.20(1.06-1.37)$ & 0.005 & 0 & 0.54 \\
\hline RC & 2 & $0.91(0.60-1.40)$ & 0.68 & 0 & 0.50 \\
\hline Type of CVD & & & & & \\
\hline CHD & 5 & $1.44(1.13-1.84)$ & 0.004 & 59 & 0.04 \\
\hline MI & 5 & $1.01(0.68-1.51)$ & 0.95 & 0 & 0.53 \\
\hline Sample size & & & & & \\
\hline $\begin{array}{l}\text { More than } 1000 \\
\text { subjects }\end{array}$ & 4 & $1.18(1.04-1.34)$ & 0.01 & 0 & 0.52 \\
\hline Less than 1000 subjects & 6 & $1.64(1.12-2.41)$ & 0.01 & 48 & 0.09 \\
\hline
\end{tabular}

CC, case-control study; PC, prospective cohort study; RC, retrospective cohort study; CVD, cardiovascular disease; CHD, coronary heart disease; MI, myocardial infarction

association between PCOS and the risk of CVD. Ten studies involving more than 100000 individuals were included in our meta-analysis. The results suggested that PCOS was a risk factor of the increased risk of CVD. In a stratified analysis by type of CVD, a significant association was found between PCOS and CHD. However, no significant association was observed between PCOS and
MI. Two previous meta-analyses also found that women with PCOS appeared to be at increased risk of CHD [17, 18]. Thus, this present study had three advantages. First, more studies were included in this meta-analysis. Second, we investigated the association between PCOS and MI risk for the first time. Third, sensitivity analysis and Galbraith plot were investigated in this meta-analysis.

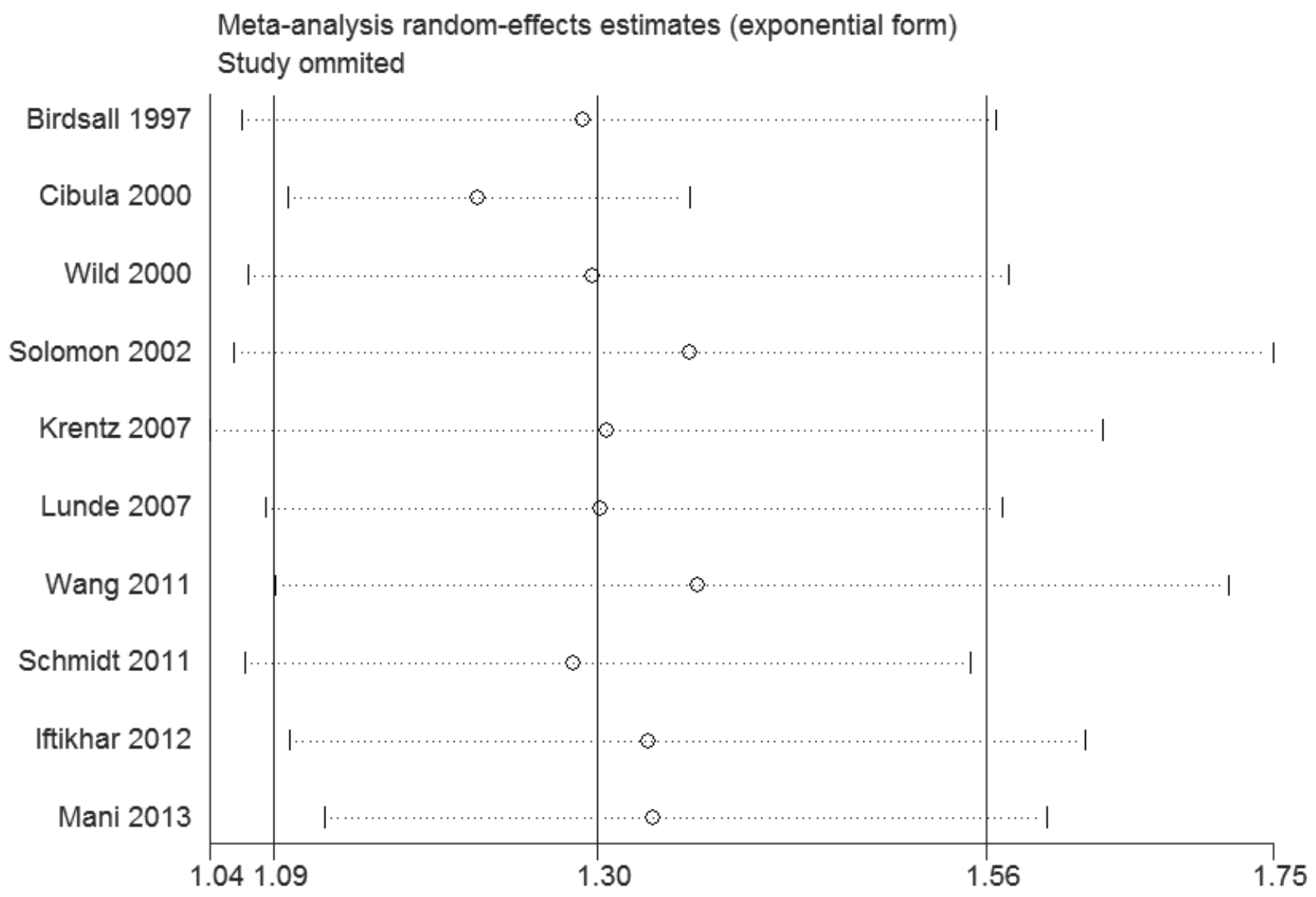

Figure 3: Sensitivity analysis of the association between PCOS and CVD. 
A recent meta-analysis determined the relationship between PCOS and CVD risk markers [19]. That study suggested that PCOS patients had significantly elevated homocysteine, dimethylarginine, and lipoprotein, et al. [19]. In addition, Ozegowska et al. indicated that PCOS patients had higher CVD risk factors, such as body mass index (BMI), waist circumference, and waist-to-hip ratio [20]. Therefore, patients with PCOS might have high risk of CVD.

This study had some advantages. First, substantial number of individuals were pooled from different trials, which significantly increased statistical power of the metaanalysis. Second, the quality of studies included in current meta-analysis was relatively satisfactory and met our predefined inclusion criteria. Third, no publication bias was found, which suggested that the result was unbiased.

Several limitations of this study must be acknowledged. Firstly, only online databases were searched; some studies may have been missed. Secondly, no studies with Asians and other races was included in this meta-analysis. Thirdly, heterogeneity was found in this study. Sensitivity analysis was used to find the source of heterogeneity. Fortunately, it was decreased when one outlier was excluded.

This study suggested that PCOS patients had significantly increased CHD risk.

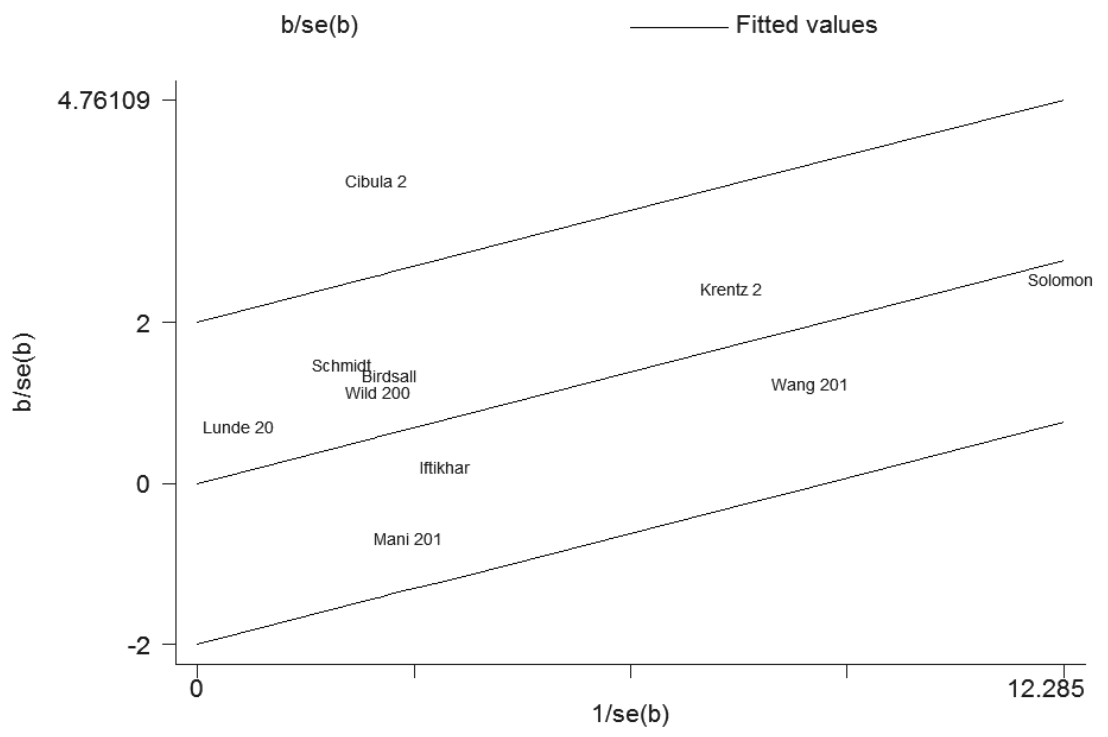

Figure 4: Galbraith plot of the association between PCOS and CVD.

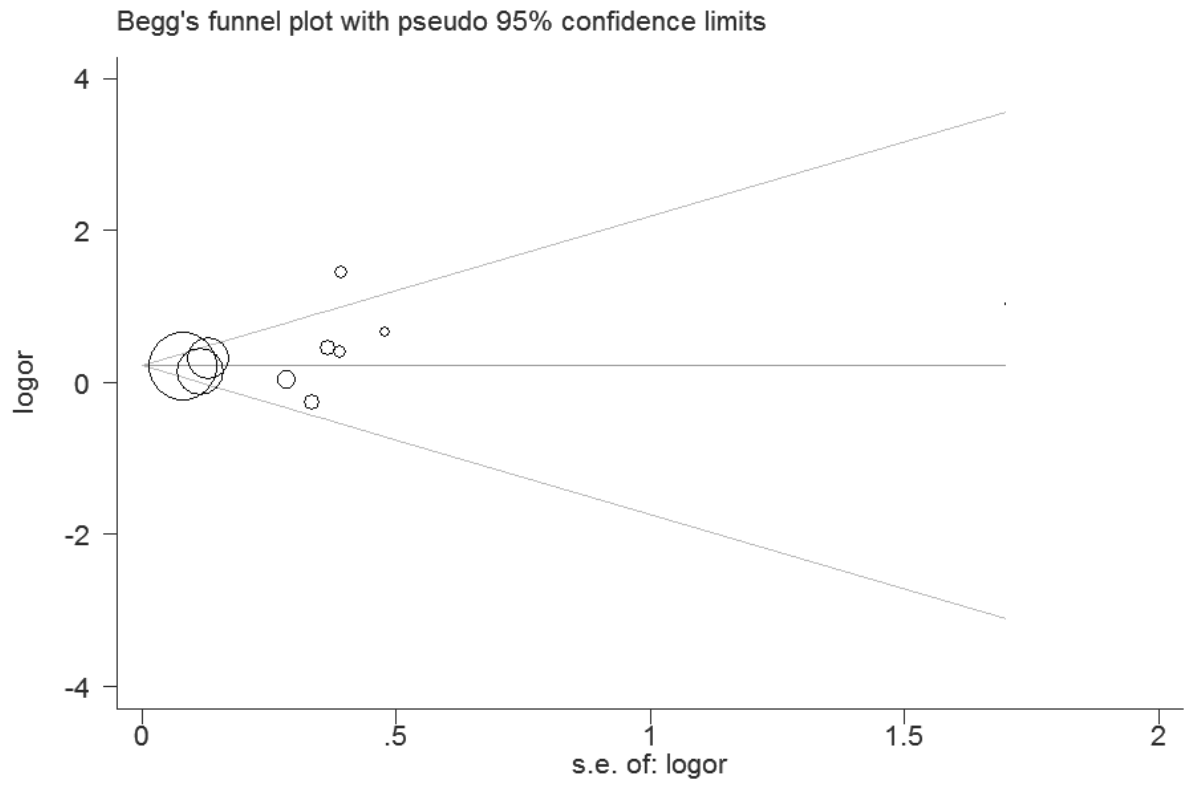

Figure 5: Funnel plot of the association between PCOS and CVD. 


\section{MATERIALS AND METHODS}

\section{Publication search}

PubMed, Science Direct, EMBASE, and Cochrane Library databases were searched by two independent authors (LQ Zhao and ZG Zhu). Last search was updated in Apr, 2016. The search terms were used as follows: (polycystic ovary syndrome or PCOS) and (cardiovascular diseases or CVD). No publication date or language restrictions were imposed. We contacted primary authors to clear doubts. The reference list of obtained articles is showed in the supplemental material.

\section{Study selection}

The selection criteria of the retrieved articles in our meta-analysis were as follows: a) case-control studies or cohort studies; b) studies evaluating the association between PCOS and risk of CVD; c) sufficient data available to calculate an odds ratio (OR) with $95 \%$ confidence interval (CI). The exclusion criteria of the meta-analysis were: a) case-only studies; b) studies with incomplete data; and c) meta-analyses, letters, reviews, and editorial articles. If more than one study was published by the same author using the same patient population or overlapping case series, the study with the largest size of samples was included.

\section{Data extraction and qualitative assessment}

Two investigators extracted data from the included studies independently, and the respective studies were retrieved for further consideration if judged pertinent by one or two reviewers. Any discrepancies were identified and resolved by consensus. For each study, the following data were extracted: first author's name, year of publication, study design, race, age, duration of followup, sample size, outcomes, and covariant. A modification of the Newcastle-Ottawa Scale (NOS) was used as an assessment tool for selection, comparability, and outcome assessment. The studies should (1) brief description of appropriateness of studies assembled for assessing the hypothesis; (2) rationale for the selection and coding of data (eg. Roterdam PCOS Consensus, NIH criteria); (3) documentation of how data were classified (eg. multiple raters blinding, interrater reliability); (4) assessment of confounding variables (eg, comparability of cases and controls in studies where appropriate); (5) assessment of heterogeneity.

\section{Statistical analysis}

The strength of the association between PCOS and CVD risk was estimated by calculating ORs with 95\% CIs. Tests for heterogeneity were made among studies using the Cochran's $\mathrm{Q}$ and $\mathrm{I}^{2}$ test statistic. For the Cochran's $Q$ test statistic, a $P$ value $<0.10$ was accepted as statistically significant heterogeneity. Random-effects models were used to estimate summary ORs and 95\% CIs. We also conducted subgroup analyses by study design, type of outcomes, and sample size. Galbraith plot was also performed to identify sources of heterogeneity. Sensitivity analyses were conducted to assess the strength of our findings by excluding one study at a time. Begg's funnel plot and Egger's regression test were used to evaluate publication bias. In Egger's test, when $P$ value $<0.10$, it was considered statistically significant publication bias. All analyses were conducted using Stata v.12 (StataCorp LP, TX) statistical software.

\section{CONFLICTS OF INTEREST}

The authors declare that they have no conflicts of interest.

\section{REFERENCES}

1. Azziz R, Woods KS, Reyna R, Key TJ, Knochenhauer ES, Yildiz BO. The prevalence and features of the polycystic ovary syndrome in an unselected population. J Clin Endocrinol Metab. 2004 Jun;89:2745-9.

2. Asunción M, Calvo RM, San Millán JL, Sancho J, Avila S, Escobar-Morreale HF. A prospective study of the prevalence of the polycystic ovary syndrome in unselected Caucasian women from Spain. J Clin Endocrinol Metab. 2000 Jul;85:2434-8.

3. Franks S. Polycystic ovary syndrome. N Engl J Med. 1995 Sep 28;333:853-61.

4. Mathers CD, Loncar D. Projections of global mortality and burden of disease from 2002 to 2030. PLoS Med. 2006;3:e442.

5. Celermajer DS, Ayer JG. Childhood risk factors for adult cardiovascular disease and primary prevention in childhood. Heart. 2006 Nov;92:1701-6.

6. Oskui PM, French WJ, Herring MJ, Mayeda GS, Burstein $\mathrm{S}$, Kloner RA. Testosterone and the cardiovascular system: a comprehensive review of the clinical literature. J Am Heart Assoc. 2013 Nov 15;2:e000272.

7. Birdsall MA, Farquhar CM, White HD. Association between polycystic ovaries and extent of coronary artery disease in women having cardiac catheterization. Ann Intern Med. 1997 Jan 1;126:32-5.

8. Cibula D, Cífková R, Fanta M, Poledne R, Zivny J, Skibová J. Increased risk of non-insulin dependent diabetes 
mellitus, arterial hypertension and coronary artery disease in perimenopausal women with a history of the polycystic ovary syndrome. Hum Reprod. 2000 Apr;15:785-9.

9. Wild S, Pierpoint T, McKeigue P, Jacobs H. Cardiovascular disease in women with polycystic ovary syndrome at long-term follow-up: a retrospective cohort study. Clin Endocrinol (Oxf). 2000 May;52:595-600.

10. Solomon CG, Hu FB, Dunaif A, Rich-Edwards JE, Stampfer MJ, Willett WC, Speizer FE, Manson JE. Menstrual cycle irregularity and risk for future cardiovascular disease. J Clin Endocrinol Metab. 2002 May;87:2013-7.

11. Krentz AJ, von Mühlen D, Barrett-Connor E. Searching for polycystic ovary syndrome in postmenopausal women: evidence of a dose-effect association with prevalent cardiovascular disease. Menopause. 2007 MarApr;14:284-92.

12. Lunde O, Tanbo T. Polycystic ovary syndrome: a followup study on diabetes mellitus, cardiovascular disease and malignancy 15-25 years after ovarian wedge resection. Gynecol Endocrinol. 2007 Dec;23:704-9.

13. Schmidt J, Landin-Wilhelmsen K, Brännström M, Dahlgren E. Cardiovascular disease and risk factors in PCOS women of postmenopausal age: a 21-year controlled follow-up study. J Clin Endocrinol Metab. 2011 Dec;96:3794-803.

14. Wang ET, Cirillo PM, Vittinghoff E, Bibbins-Domingo $\mathrm{K}$, Cohn BA, Cedars MI. Menstrual irregularity and cardiovascular mortality. J Clin Endocrinol Metab. 2011 Jan;96:E114-8.
15. Iftikhar S, Collazo-Clavell ML, Roger VL, St Sauver J, Brown RD Jr, Cha S, Rhodes DJ. Risk of cardiovascular events in patients with polycystic ovary syndrome. Neth $\mathrm{J}$ Med. 2012 Mar;70:74-80.

16. Mani H, Levy MJ, Davies MJ, Morris DH, Gray LJ, Bankart J, Blackledge H, Khunti K, Howlett TA. Diabetes and cardiovascular events in women with polycystic ovary syndrome: a 20-year retrospective cohort study. Clin Endocrinol (Oxf). 2013 Jun;78:926-34.

17. de Groot PC, Dekkers OM, Romijn JA, Dieben SW, Helmerhorst FM. PCOS, coronary heart disease, stroke and the influence of obesity: a systematic review and metaanalysis. Hum Reprod Update. 2011 Jul-Aug;17:495-500.

18. Anderson SA, Barry JA, Hardiman PJ. Risk of coronary heart disease and risk of stroke in women with polycystic ovary syndrome: a systematic review and meta-analysis. Int J Cardiol. 2014 Sep 20;176:486-7.

19. Toulis KA, Goulis DG, Mintziori G, Kintiraki E, Eukarpidis E, Mouratoglou SA, Pavlaki A, Stergianos S, Poulasouchidou M, Tzellos TG, Makedos A, Chourdakis M, Tarlatzis BC. Meta-analysis of cardiovascular disease risk markers in women with polycystic ovary syndrome. Hum Reprod Update. 2011 Nov-Dec;17:741-60.

20. Ozegowska K, Pawelczyk L. Cardiometabolic risk in patients with polycystic ovary syndrome. Ginekol Pol. 2015 Nov;86:840-8. 